\title{
Study of Numerical Simulation and Optimization on Daylight of an Underground Transportation Hub in Tianjin
}

\author{
Yangyang $\mathrm{Wu}^{1, \mathrm{a}}$, Wei $\mathrm{Li}^{1, \mathrm{~b}}$ Yan Wang ${ }^{2, \mathrm{c}}$ \\ ${ }^{1}$ Institute of green architecture technology and Application, Tianjin Chengjian University, Jinjing \\ Street, Tianjin, China \\ ${ }^{2}$ Zhejiang South Architectural design Co.,Ltd, 34\#No.36 Baiyun Road,Hangzhou \\ a772871847@qq.com, bliweiliwei75@126.com, `southhb@126.com
}

\begin{abstract}
Keywords: underground space;transportation hub;daylighting;numerical simulation
Abstract. In this paper, the daylight of an underground transportation hub in Tianjin is studied by using the method of numerical simulation. It can be seen from the numerical simulation results that the average illumination in the waiting halls is $3620.64,4497.60$ and $2178.97 \mathrm{~lx}$ in the vernal equinox and autumn equinox, summer solstice and winter solstice respectively, while that of the platform layer is 34.97, 43.79 and 21.10 1x. By optimizing the original daylight design of the platform, the average illumination has increased by $40 \%$ and has reached $51.7,64.86$ and $31.281 \mathrm{x}$. The average illumination of the escalator below the pitted hall is 99.29 lx. By optimizing the design, the average illumination has reached $209.421 \mathrm{x}$.
\end{abstract}

\section{Introduction}

In the process of using the underground space, the light environment problem becomes more and more important. The natural lighting design not only affects people's physical and mental health, but also has a very important significance for building energy conservation. The actual survey found that most of the underground rail transit stations did not make full use of their lighting conditions, all using artificial lighting, which is a waste of energy and reduces comfort [1-7].

In this paper, the Radiance IES module in the integrated building performance analysis software is used to analyze and optimize the natural lighting conditions of the underground space in a transportation hub in Tianjin, and to provide some references for the natural lighting design and energy saving evaluation of underground space.

\section{Research object}

The research object of this paper is a large-scale underground transport hub extending from Beijing-Tianjin inter-city extension to Tianjin Binhai New Area. The hub is designed for three underground floors. The maximum underground depth is about $33 \mathrm{~m}$, and the total construction area is about $260,000 \mathrm{~m}^{2}$. The maximum underground depth is about $33 \mathrm{~m}$, and the total construction area is about $260,000 \mathrm{~m}^{2}$. The ground is designed with a "shell" shape dome structure, and the main function of the ground floor is the entrance hall, through which passengers can go down to the waiting area in the first floor underground Underground under the dome open oval big hole, open hole below the ground floor of the inter-city train station waiting room, ticket office, out of the hall and office management, equipment and other housing. The second basement is an inter-city railway station and a metro station with two lines. The size of the inter-city railway station is three six lines and the underground three floors are a metro station platform[8].

The research content of this paper includes: (1) natural light simulation analysis of the waiting hall on the first floor; (2) simulation and optimization of natural lighting on the second basement platform; (3) natural lighting simulation optimization in and out of the station hall. 


\section{Establishment of numerical simulation model and setting of related parameters}

According to the data and information collected in the research, a model is established (Figure 1) based on the research content and related standards. The building model is $220 \mathrm{~m}$ long and $60.5 \mathrm{~m}$ wide. The height of the ground floor is $0 \mathrm{~m}$, the height of the first ground floor is $11 \mathrm{~m}$, and the height of the second ground floor is $19.8 \mathrm{~m}$.

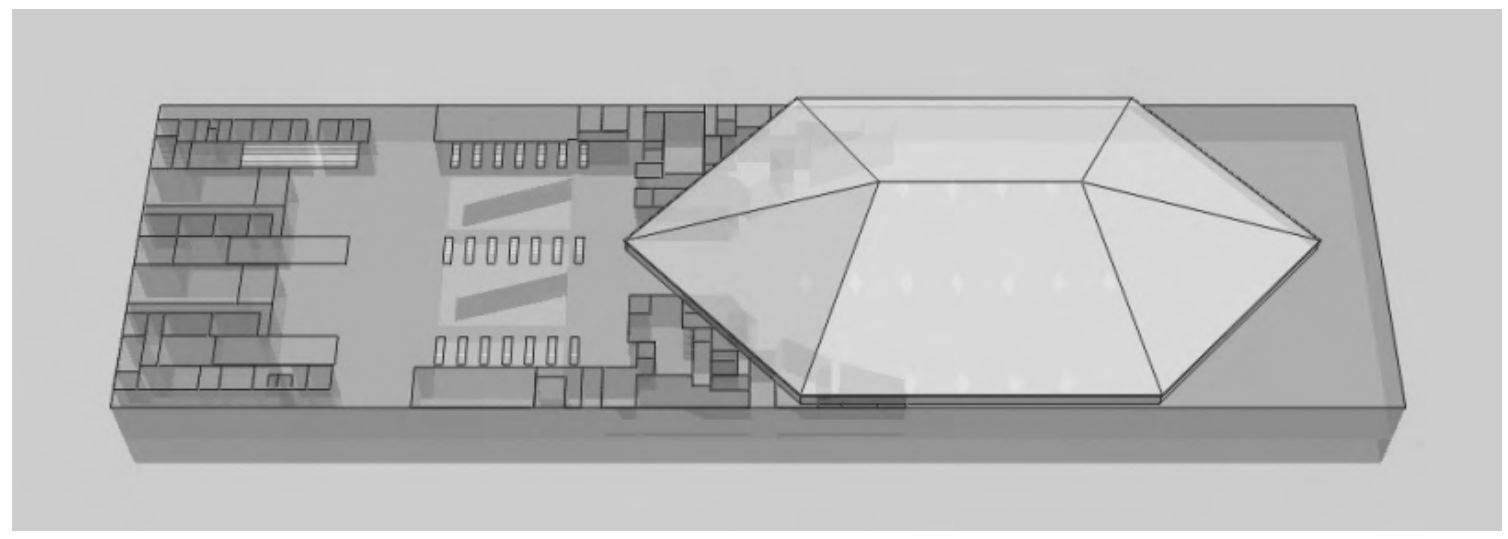

Figure 1 Numerical simulation model

(1) Waiting hall. The top roof of the waiting room is open to the roof (see Figure 2) with an opening area of 3,600 $\mathrm{m}^{2}$. Under the condition of the same area and integrated light transmittance, the simplified model of the part underneath the "shell" dome structure of the model was established to facilitate the numerical simulation.

(2) Platform layer. On the premise of not destroying the structural system, combined with the layout of the building, ensures the feasibility of the underground two-layer integrated pipeline to set a reasonable number of openings. A total of 15 diamond lighting ports (see Figure 3), (each lighting port area of $6.65 \mathrm{~m}^{2}$, the total open area of about $100 \mathrm{~m}^{2}$ ), accounts for $0.68 \%$ of the public area of the station,

Taking into account the people inside the station hall and the glass to block the light, these will set the glass roof transmittance to 0.50 .

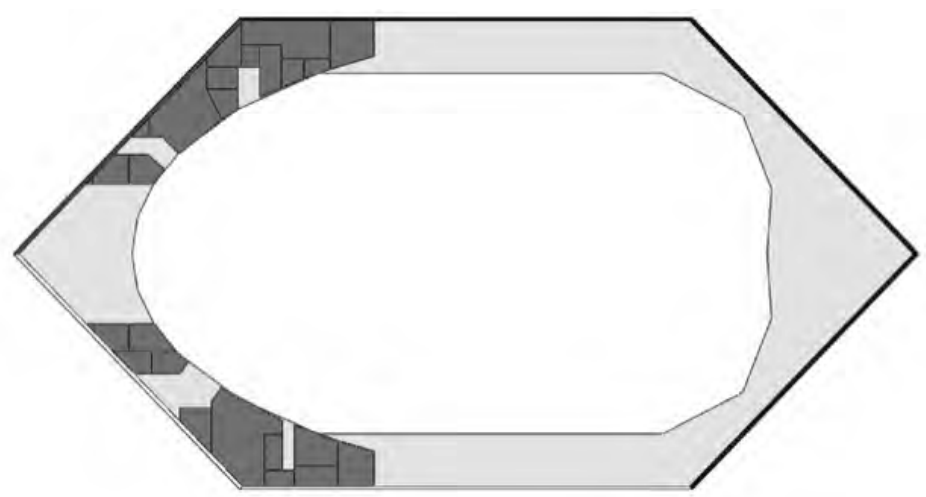

Figure 2 Waiting room roof openings 


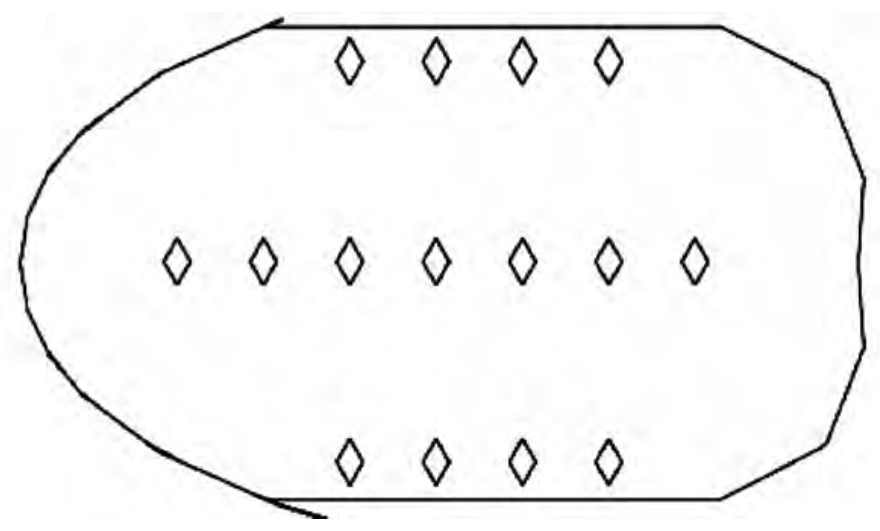

Figure 3 Waiting room plate hole

(3) Passenger Stand Room hall. The entrance hall ceiling, the board hole, and each of the three platforms roof opening light hole length $1.4 \mathrm{~m}, 5.5 \mathrm{~m}$ wide, a total of 7 , each spacing of $3.8 \mathrm{~m}$, lighting area of $53.9 \mathrm{~m}^{2}$; Lighting port length $22 \mathrm{~m}$, width $17.3 \mathrm{~m}$, lighting port area $380.6 \mathrm{~m}^{2}$. The ceiling of the north exit hall is open to the ceiling. The length of the roof opening of each platform at each of the three platforms is $20.7 \mathrm{~m}$ long and $5.7 \mathrm{~m}$ wide. The lighting area is $118 \mathrm{~m}^{2}$ (see Figure 4 and Figure 5). Light transmittance and glass transmittance are set to 0.70 .

The underground transport hub is located in Tianjin (latitude $39^{\circ} 06^{\prime}$, longitude $117^{\circ} 10^{\prime}$ east) and belongs to the category III photothermal climate zone. Tianjin climate belongs to warm temperate,semi-humid,continental monsoon climate And four distinct seasons. During the winter solstice, the midday sun altitude is $27^{\circ} 54$ '; at midday, the midday sun altitude is $73^{\circ} 51^{\prime}$, and the midday solar elevation angle varies throughout the year.

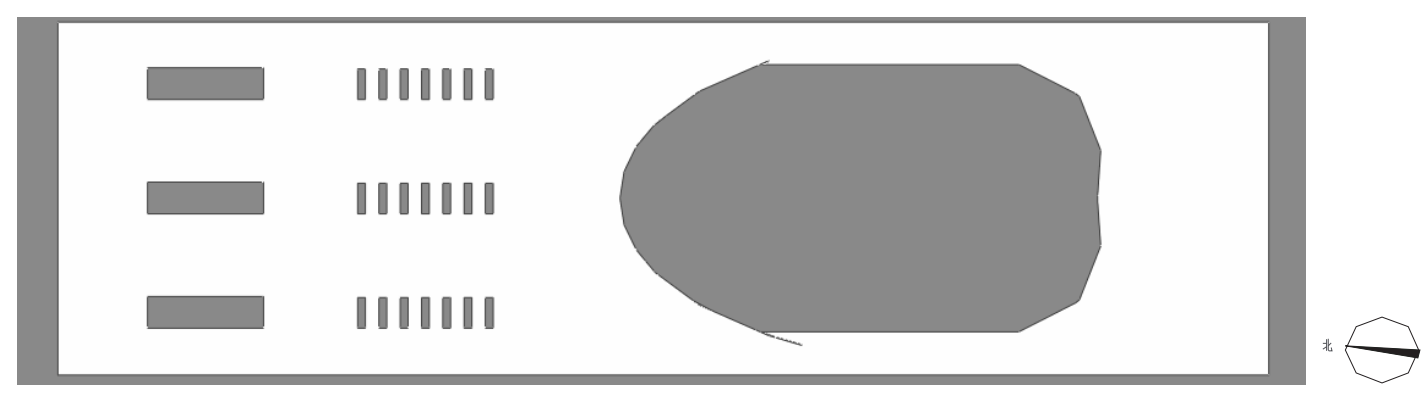

Figure 4 North station hall, pit hall ceiling opening

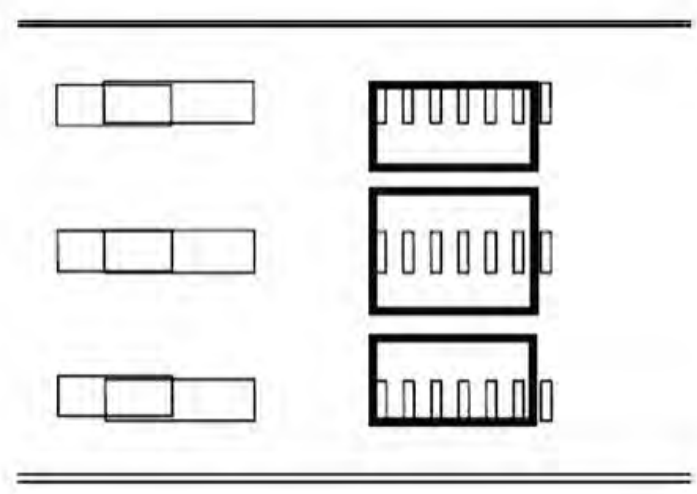

Figure 5 Entrance hall plate hole

As the vernal equinox and autumn equinox sky and sun incident conditions that are basically the same, in order to simplify the workload, this article no longer simulates the equinox daylighting 
situation, and the autumn equinox simulation result represents the spring and autumn equinox daylighting situation. The simulated dates were June 21st (summer solstice), September 23rd (autumn equinox) and December 22nd (winter solstice) respectively. The CIE standard full cloudy day was taken as the research scene.

\section{Simulation results and analysis}

\section{Waiting hall lighting simulation}

Through the lighting simulation, the data of illumination and illumination (see Table 1) and the distribution of illumination (see Figure 6-8) in the spring and autumn, summer solstice and winter solstice waiting hall were obtained.

Table 1 Waiting hall illumination average and the average value of the lighting coefficient

\begin{tabular}{|l|l|l|}
\hline season & Illumination average /lx & Daylight factor average $/ \%$ \\
\hline Spring and autumn points & 3620.64 & 24.9 \\
Summer solstice & 4497.60 & 24.8 \\
Winter solstice & 2178.97 & 24.8 \\
\hline
\end{tabular}
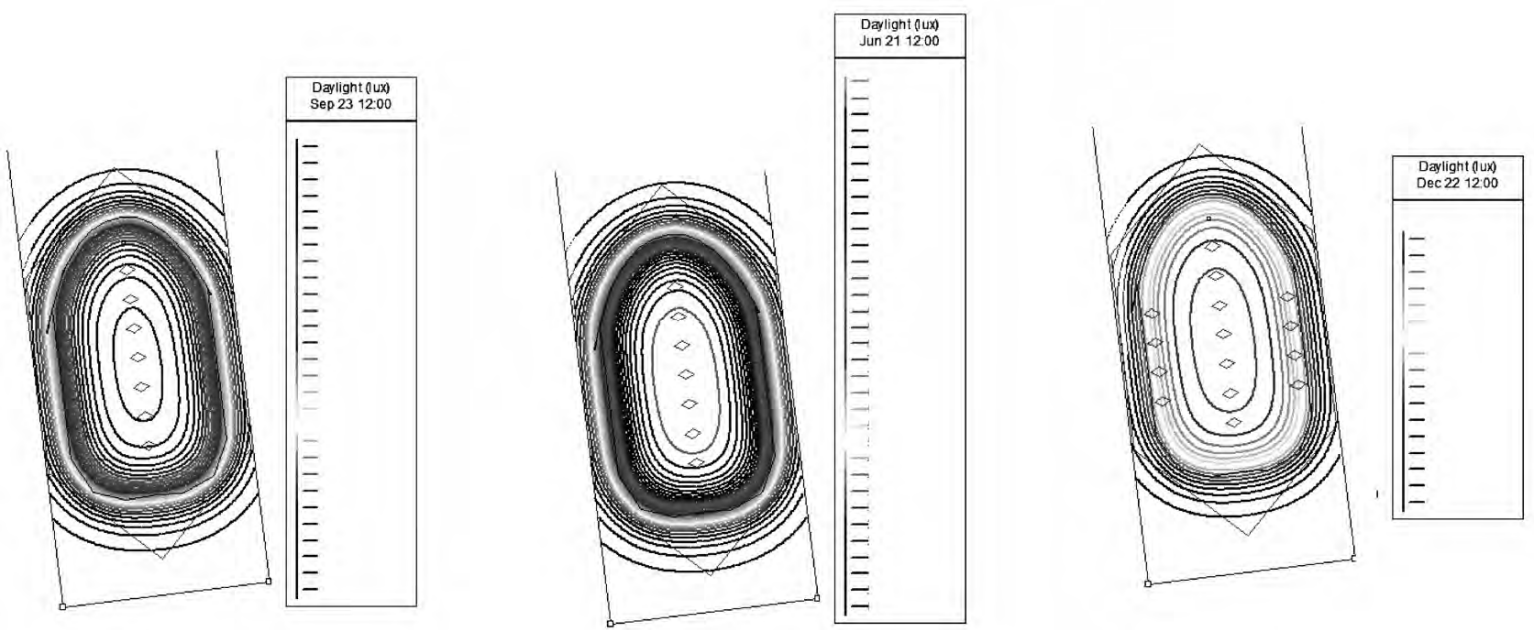

Figure 6 Autumn illumination numerical simulation

Figure 7 Summer solstice illumination numerical simulation

Figure 8 Winter solstice illumination numerical simulation

The results showed that the average waiting time of spring equinox and autumn equinox was $3620.64 \mathrm{~lx}$, the average value of summer solstice was $4497.60 \mathrm{~lx}$, and the average of winter solstice was $2178.97 \mathrm{~lx}$, which satisfied the basic requirements of natural lighting. At the same time, indirect lighting was also available in the rooms surrounding the waiting hall and the ticket office.

\section{Site lighting simulation and optimization}

In the original lighting design scheme, the lighting openings of the platform were designed as a total of 15 diamonds, each of which had an area of $6.65 \mathrm{~m}^{2}$, with a total opening area of about $100 \mathrm{~m}^{2}$.

The reflectance of the inner surface of the platform is 0.70 on the inner surface, 0.20 on the ground and 0.90 on the ceiling respectively. When the transmittance of the glazing glass is set to 0.50 , the illumination data (see Table 2) and the layout of the platform layer are obtained (see Figure 9-11). 
Table 2 Illuminance average of platform layer in case of open diamond window $1 \mathrm{x}$

\begin{tabular}{|c|c|}
\hline season & Illumination average /lx \\
\hline Spring and autumn points & 34.97 \\
Summer solstice & 43.79 \\
Winter solstice & 21.10 \\
\hline
\end{tabular}
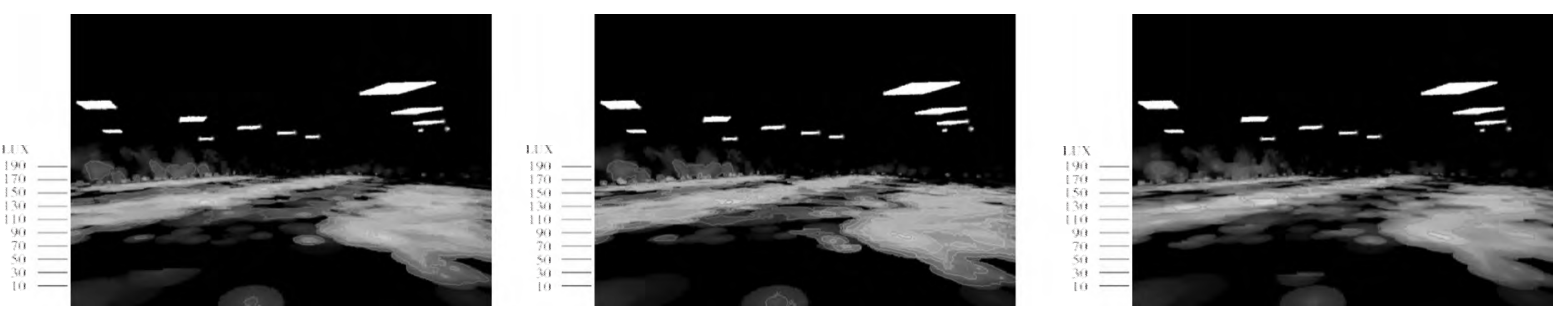

Figure 9 Spring and autumn illumination distribution

Figure 10 Summer solstice illumination distribution

Figure 11 Winter solstice illumination distribution

According to the standard values of normal lighting for various places in urban rail transit, the illumination of the station and lobby (underground) should reach 200 1x[9]. Therefore, the use of the platform with the diamond-shaped lighting port cannot meet the lighting requirements and therefore artificial lighting needs to be added.

According to the lighting theory, it can be seen that, in terms of the amount of light, the amount of light in the square window is highest when the area of the window opening is the same, and the number of the light outlets also has a great influence on the lighting efficiency[10]. According to the above theory, the author optimized the lighting design scheme by introducing two kinds of optimization schemes (Design a and b), as shown in Figure 12.

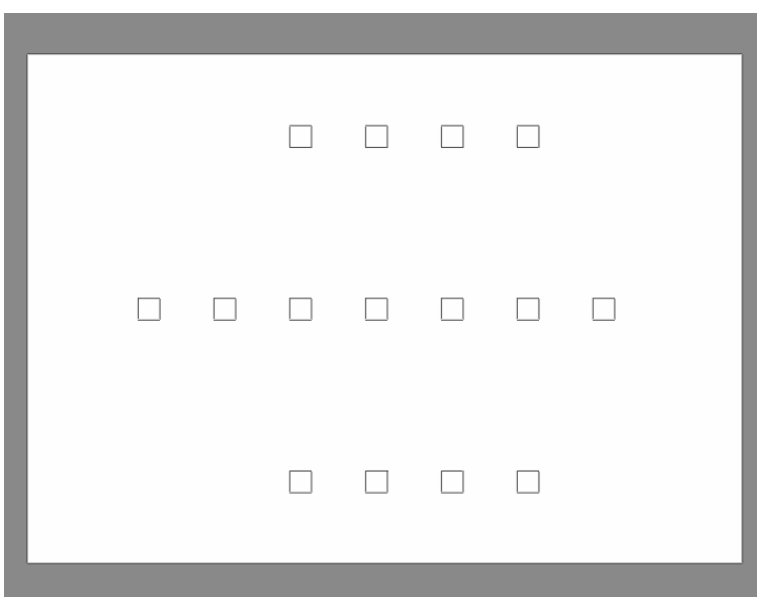

(a) 15 square light port distribution

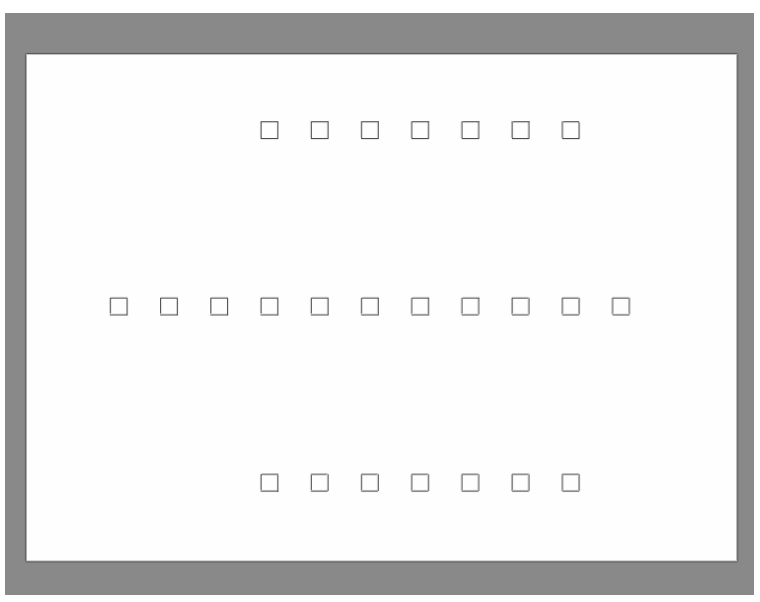

(b) 25 square light port distribution

Figure 12 Square light port distribution

Plan a: The number and area of the lighting openings are unchanged However, the shape changes; 15 square openings in the same position are shown in Figure 12a. Each lighting opening area is 6.65 $\mathrm{m}^{2}$ and the total opening area is about $100 \mathrm{~m}^{2}$. Perform the simulation again under the same conditions to obtain the following data (see Table 3). 
Table 315 square window openings the average floor illumination $1 \mathrm{x}$

\begin{tabular}{|l|l|}
\hline season & Illumination average $/ \mathrm{lx}$ \\
\hline Spring and autumn points & 36.46 \\
Summer solstice & 45.73 \\
Winter solstice & 22.15 \\
\hline
\end{tabular}

The above lighting simulation data shows that in the same area and the same number of lighting port, the lighting effect of square lighting port is better than that of the diamond design, the average value of spring and autumn illumination is increased from $34.97 \mathrm{~lx}$ to $36.46 \mathrm{~lx}$; the average value of summer solstice illumination is increased from $43.79 \mathrm{~lx}$ to $45.73 \mathrm{~lx}$; the average of winter solstice illumination increased from $21.10 \mathrm{~lx}$ to $22.15 \mathrm{~lx}$, and the average illuminance increased by $4 \%-5 \%$.

Plan b: The total area of the lighting port is unchanged However, the number changes; the square lighting port in the area of the original lighting port is re-arranged so each of the lighting port area is $4 \mathrm{~m}^{2}$, for a total of 25 , as shown in Figure $12 \mathrm{~b}$, with a total area of $100 \mathrm{~m}^{2}$; Perform the simulation again under the same conditions to obtain the following data, as shown in Table 4.

Table 425 square window openings the average floor illumination $1 \mathrm{x}$

\begin{tabular}{|l|l|}
\hline season & Illumination average /lx \\
\hline Spring and autumn points & 51.70 \\
Summer solstice & 64.86 \\
Winter solstice & 31.28 \\
\hline
\end{tabular}

From the above data, it can be seen that under these conditions the total area of the lighting port remains the same, the area of a single lighting port is reduced and the number of lighting ports is increased. The mean values of the equinox and the autumn equinox are increased from $36.46 \mathrm{~lx}$ to $51.70 \mathrm{~lx}$; the mean value of the summer solstice illuminance is increased from 45.73 lx to $64.861 \mathrm{x}$; winter solstice illumination average increased from $22.15 \mathrm{~lx}$ to $31.28 \mathrm{~lx}$, and illumination average increased by about $40 \%$. Lighting efficiency is greatly improved, artificial lighting is effectively reduced and conservation of energy is increased.

\section{Lighting simulation and optimization of entrance and exit hall}

Analog parameters settings: equinox, CIE standard overcast sky. The inner surface of the wall reflectance is 0.70 , the ground 0.20 , and roof 0.90 . the transmittance of the glazing glass is set to 0.70 . After simulation, the following data is obtained: the average illuminance of the ground floor below the ceiling of the north exit hall is $665.52 \mathrm{~lx}$, and the average illuminance of the ground floor below the opening of the ceiling of the entrance hall is $364.96 \mathrm{~lx}$. The average illuminance of the escalator below the hole is 99.29 lx. The station entrance hall and the north exit hall roof openings are designed for the introduction of natural light. Therefore light can be directly exposed to the platform layer, into the hall plate hole. Thus part of the natural light is led to the ground floor. Lighting effects are shown in Figure 13. 


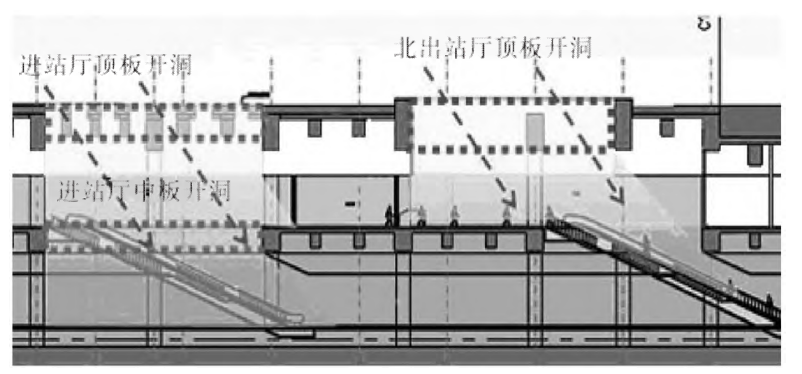

Figure 13 entrance and exit hall natural lighting effects

Through the simulation results it can be seen that the entrance hall ceiling hole lighting efficiency is low. According to the standard value of normal lighting for various places in urban rail transit, the illumination of station stairs and escalators should reach $150 \mathrm{~lx}$. The original plan cannot meet the standard.

Therefore, we try to change the way of opening the lighting hole. Taking a platform as an example, simulate it again under the same conditions to keep the total area of the lighting hole constant, and change the position and size of the lighting hole. The average illumination has not changed a lot. Therefore, it should be appropriate to increase the light port area. Cancel the spacing between the seven lighting ports, to a continuous one lighting port. The ground floor below the entrance hall roof hole average illuminance is $892.97 \mathrm{~lx}$, and escalator below the plate openings average illuminance is $369.17 \mathrm{~lx}$, greatly exceeding the normal lighting standard value, resulting in unnecessary waste. The final solution is further optimized as follows: increase the length of seven lighting ports from $1.4 \mathrm{~m}$ to $2.1 \mathrm{~m}$, and keep the same width, i.e. 1.5 times the area of the lighting port. Illumination data and distribution are shown in Table 5 and Figure 14.

Table 5 Entrance hall under the ground openings and escalators below the average illuminance $1 \mathrm{x}$

\begin{tabular}{|l|l|}
\hline Location & Illumination average /1x \\
\hline Ground floor below the entrance hall roof hole & 590.71 \\
Escalator below the plate openings & 209.42 \\
& \\
\hline
\end{tabular}

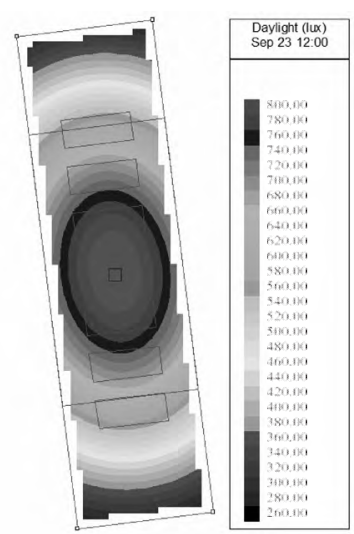

Figure 14 Numerical Simulation of Ground Illumination Under the Roof Opening of Entrance Hall

\section{Conclusions}

The average illuminance of the vernal equinox and autumn equinox, the summer solstice and the winter solstice in the underground space of a transportation hub in Tianjin is 3620.64, 4497.60 and $2178.971 \mathrm{x}$ respectively. The basic requirements of natural daylighting are met. The surrounding rooms and ticket offices can also obtain indirect natural lighting. Platform level the vernal equinox and autumn equinox, summer solstice and winter solstice average illuminance were 34.97, 43.79, 
$21.101 \mathrm{x}$ respectively. After optimization of lighting design, the average illuminance increased by about 40\%, 51.7, 64.86, 31.28 lx respectively, and lighting efficiency increased dramatically. Escalator below the escalator hall entrances average illumination is 99.29 1x. And after optimization of lighting design, illumination average increased to $209.42 \mathrm{~lx}$, to meet the requirements of the relevant standards.

From the research in this paper, it can be seen that the underground building space has the feasibility of natural lighting through reasonable lighting design and technical means, and has great potential for energy saving. At the same time, using numerical simulation means to study the lighting in underground space will help to improve the efficiency and accuracy of the design of lighting scheme, so as to obtain the optimal design scheme.

In addition, due to structural system and function limitations, natural lighting cannot be achieved in some areas of underground space, and more advanced techniques such as light pipe systems are needed, and further exploration will be conducted in future studies.

\section{Acknowledgements}

This work was supported by Tianjin Science and Technology Support Project (Grant Numbers 15ZCZDSF00080); Tianjin Science and Technology Support Project (Grant Numbers 16PTGCCX00060);National Key R\&D Program of China（Grant No.2016YFC0700201）.

\section{References}

[1] DANNY H, JOSEPH C L. An investigation of daylighting performance and energy saving in a daylitcorri dor[J]. Energy and Buildings, 2003(35): 365-373.

[2] JUN Ji, NI Shi. Planning and design of underground space use[J]. Memories of the School of Engineering, 1997(1): 48-93.

[3] KIM J T, KIM G . Overview and new developments in optical daylighting systems for building a healthy indoor environment[J]. Building and Environment, 2010(45): 256-269.

[4] G·Z Brown, Mark Dekai. Solar radiation, Wind, Natural light [M].

[5] Chang Huaisheng. Architectural Environmental Psychology[M]. Beijing: China Architecture \& Building Press, 1990.

[6] Coster. Dynamic Natural Lighting Architecture Principles and Applications: Fundamental Design System Project Case [M]. Wang Hongwei, Trans. Beijing: China Electric Power Press, 2007.

[7] Du Fang, LI Yong, WU Feng. Energy Saving Lighting Design of Underground Buildings[J]. Building Energy Efficiency, 2011(1):68-70.

[8] Xing Jiayong. Natural Lighting Design of Underground Junction at Yujiapu Station[J]. Shanxi Architecture, 2012, 38(4): 18-19.

[9] GB/T 16275-2008, Urban Rail Traffic Lighting [S].

[10]Liu Xiaotu. Construction Physics [M]. Beijing: China Architecture \& Building Press, 2010. 